\title{
Predictors of Cognitive Impairment Severity in Rural Patients at a Memory Clinic
}

\author{
Catherine Lacny, Andrew Kirk, Debra G. Morgan, Chandima Karunanayake
}

\begin{abstract}
Objective: Patients with dementia benefit from early assessment and diagnosis. In an attempt to identify factors leading to delay in referral, we investigated socio-demographic, clinical, and functional predictors of greater severity of cognitive impairment in dementia patients presenting to a memory clinic in Saskatoon, Saskatchewan. Methods: Data collection began in 2004 at the Rural and Remote Memory Clinic in Saskatoon, where non-institutionalized patients were referred by their family physicians. The patient and caregiver questionnaires and assessments administered at the clinic day appointment provided the socio-demographic, clinical, and functional patient variables, as well as the caregiver stress and burden variables. The dependent variable was patient cognitive impairment, as measured by Modified Mini-Mental State Examination (3MS) scores. Variables underwent univariate linear regression with 3MS scores in order to determine possible associations. A multiple regression analysis was conducted to determine predictors of cognitive impairment severity at clinic presentation. Results: Our sample included 198 patients (62\% female). The mean age was 73.9 years $(\mathrm{SD}=9.2)$. We found that an age and gender interaction, years of formal education, Functional Activities Questionnaire score, and Brief Symptom Inventory score were significantly associated with 3MS scores $(\mathrm{p}<0.05)$. Conclusions: Increased cognitive impairment at presentation was predicted by fewer years of formal education, poorer functional ability, and less caregiver psychological distress. There was a significant interaction between age and gender: younger females were more cognitively impaired than younger males at clinic day, while in older patients, males were more cognitively impaired than females.
\end{abstract}

RÉSUMÉ: Facteurs prédisposant à un déficit cognitif plus sévère chez les patients d'un milieu rural traités à une clinique de la mémoire. Objectif : Les patients atteints de démence bénéficient d'une évaluation et d'un diagnostic précoces. Nous avons examiné les facteurs de prédiction sociodémographiques, cliniques et fonctionnels d'un déficit cognitif plus sévère chez les patients atteints de démence lors de leur première consultation à une clinique de la mémoire à Saskatoon, en Saskatchewan, afin d'identifier les facteurs qui contribuent à une orientation plus tardive de ces patients vers un spécialiste. Méthode : Nous avons commencé à recueillir les données en 2004 à la Rural and Remote Memory Clinic à Saskatoon, une clinique de la mémoire où les patients externes sont référés par leur médecin de famille. Les données sociodémographiques, cliniques et fonctionnelles des patients ainsi que le niveau de stress et le fardeau rapporté par les soignants ont été recueillis au moyen de questionnaires et d'évaluations faites chez les patients et les soignants au moment de la visite initiale à la clinique. La variable dépendante était le déficit cognitif du patient mesuré par l'échelle de statut mental modifié (3MS). Nous avons utilisé une analyse de régression linéaire univariée pour déterminer les facteurs de prédiction de la sévérité du déficit cognitif au moment de la première visite à la clinique. Résultats : Notre échantillon était composé de 198 patients, dont $62 \%$ étaient des femmes et l'âge moyen était de 73,9 ans (ÉT $=9,2)$. Nous avons constaté qu'une interaction entre l'âge et le sexe, le nombre d'années de scolarité, le score au questionnaire d'évaluation de la capacité fonctionnelle et le score à l'inventaire bref des symptômes étaient associés de façon significative aux scores du 3MS ( p < 0,05). Conclusions : Un niveau de scolarité plus faible, des capacités fonctionnelles moindres et moins de détresse psychologique chez le soignant étaient des facteurs de prédiction d'un déficit cognitif plus élevé au moment de la première consultation. Il existait une interaction significative au point de vue statistique entre l'âge et le sexe : les femmes plus jeunes avaient une atteinte cognitive plus sévère que les hommes plus jeunes au moment de leur première visite à la clinique alors que, chez les patients plus âgés, les hommes avaient une atteinte cognitive plus importante que les femmes.

Can J Neurol Sci. 2012; 39: 774-781

The prevalence of dementia is increasing worldwide. This crisis will persist with demographic trends bearing towards an aging population: it is predicted that over one million will have dementia in Canada by 2038, representing $2.8 \%$ of the Canadian population. ${ }^{1}$ As patients experience declining memory and reduced independence, severe strain is placed on health providers, health care systems, the national economy, and society in general. ${ }^{1}$ However, it is well documented that huge financial, social, and physical burden is carried by families of dementia patients ${ }^{2}$ who take on the unpaid caregiver role. There is potential for negative outcomes when caregivers, the vast majority of whom are elderly women, ${ }^{3}$ become overburdened with the task of caring for a loved one with dementia. ${ }^{4}$
Timely diagnosis of Alzheimer's disease and related dementias is an important factor influencing both patient prognosis and caregiver wellbeing. Early diagnosis can allow for

\footnotetext{
From the College of Medicine (CL), Division of Neurology (AK), Canadian Centre for Health and Safety in Agriculture (DGM, CK), University of Saskatchewan, Saskatoon, Saskatchewan, Canada.

Received March 2, 2012. Final Revisions Submitted June 5, 2012. Correspondence to: Catherine Lacny, College of Medicine, University of Saskatchewan, 123 Forsyth Crescent, Saskatoon, Saskatchewan, S7N 4H2, Canada. Email: ch1093@mail.usask.ca.
} 
identification and treatment of modifiable causes of dementia, timely initiation of pharmaceutical therapy that may alleviate symptoms, opportunity to educate both patient and family about the disease, and planning for future changes. ${ }^{5}$ Therefore, early diagnosis of dementia has significant implications for both patients and their families.

Saskatchewan is a western Canadian province with a population of approximately one million. It is home to a large rural and aging population: $35 \%$ of the population were rural dwellers in 2006, a figure above the national average of $20 \%$. $^{6}$ Approximately $15 \%$ were over age 65 in 2010 and this number is expected to increase to nearly $25 \%$ by $2036 .^{7}$ This growing population of older rural dwellers has proven to be disproportionately vulnerable to gaps and barriers in the delivery of dementia care compared to their urban counterparts. ${ }^{8}$ A 2006 study reported that the provision of health and social care services to people with dementia and their caregivers living in rural and remote settings was neglected globally. ${ }^{9}$

With a desire to increase accessibility and availability of dementia care for patients living in rural and remote areas of Saskatchewan, health care professionals and researchers in Saskatoon established the Rural and Remote Memory Clinic (RRMC) in 2004. ${ }^{10}$ The use of telehealth - electronic communications providing health care services when health professionals and patients are separated by distance - allows for follow-up appointments without inconveniencing patients and caregivers with the time and expenses of travel. The clinic goals are to provide an interdisciplinary assessment of dementia, reduce repeated patient travel, and shorten time to diagnosis. The clinic has proven to be a successful model in providing efficient, streamlined, and integrated patient care, and patient satisfaction, comfort, and convenience with the clinic and its use of telehealth videoconference technology has been well rated. ${ }^{11}$

Most studies of Alzheimer's disease concentrate on mild to moderate stages. However, due to the very nature of the disease, the great majority of cases evolve towards a stage of marked severity, which can last many years. ${ }^{12}$ Furthermore, with much research focus on risk factors for the development of the disease, few have examined how these variables contribute to disease severity at initial presentation to a specialized memory clinic. The current study investigated patient factors contributing to the presence of more advanced cognitive impairment at initial clinic presentation in rural patients presenting to a memory clinic in Saskatoon, SK.

\section{METHODS}

\section{Data Collection and Ethical Consideration}

Data collection began in March 2004 at the Rural and Remote Memory Clinic (RRMC) in Saskatoon, SK, where noninstitutionalized patients were referred by their family physicians. Referrals were made at the discretion of the family physician. Ethical approval was granted by the University of Saskatchewan Behavioural Research Ethics Board, and all patients and their families gave informed consent prior to participation. As the RRMC is directed toward patients with early stage memory loss, we assume the majority of patients are competent to provide consent, although this assumption cannot be confirmed until after the complete assessment has been conducted. For this reason, a family member was asked to witness the consent protocol for all patients. Patients were aware that family members co-signed the consent forms. Assessment began with a pre-clinic telehealth interview, followed several weeks later by a one-day in-person visit involving assessment by a neurologist, neuropsychology team, neuroradiologist, and physical therapist. Patient and family members were jointly interviewed by members of the clinic team. A standardized neuropsychological battery was administered and family members completed measures of caregiver burden, distress, and health as well as functional and behavioural ratings of the patient. All patients underwent a computed tomogram (CT) brain scan unless they had recently undergone neuroimaging. After assessment, patients and family members met with the neurologist and neuropsychology team who provided information about probable diagnosis, feedback based on the day's assessment, and recommendations for management and care. All diagnoses were made using consensus guidelines. ${ }^{13-16}$ Patients were then seen in follow-up at 6 weeks, 12 weeks, 6 months, 12 months, and annually thereafter or more often if clinically indicated.

\section{Participants}

Between 2004 and 2011, 250 non-institutionalized individuals were referred to the RRMC and attended their clinicday appointment. These patients comprise the clinic's database. Of the 250 patients, 44 (17.6\%) were diagnosed as "normal" by the RRMC team and were excluded from the study. Eight participants (3.2\%) were excluded because an alternate cognitive assessment tool was used to accommodate language preference, participation was refused, the patient quit the study, or they were unable to complete the $3 \mathrm{MS}$. In total, 198 patients remained eligible to participate in the study.

\section{Measures}

The patient and caregiver questionnaires and assessments administered at the clinic day appointment provided the sociodemographic, clinical and functional independent variables. Socio-demographic variables included: age, sex, marital status, years of formal education, ancestry, number of people living with the patient, number of comorbidities, time on clinic wait list, duration of symptoms, family history of dementia, and a measure of 'ruralness': the Metropolitan Influence Zone (MIZ) classification. ${ }^{17}$ Marital status was categorized into two groups: (1) married or common-law and (2) single, divorced, separated or widowed. Formal education was the summed total of elementary school, high school, and university/college/technical school years completed. Ancestry was categorized into three groups which included both Canadian born and immigrant patients: (1) First Nations, North American Indian, and Métis, (2) European, and (3) other, which included those of Asian or African ancestry. Patients or family were asked how many people lived with the patient, and this variable was categorized into three groups: (1) alone, (2) one other person only, and (3) two or more persons. Those included a spouse, partner, family, friend, boarder, and neighbours or staff at a senior's complex. Patients or family were asked to identify their comorbidities from a list of 22 conditions. Number of comorbidities was categorized into the following four groups: (1) no or one comorbidity, (2) two comorbidities, (3) three comorbidities and 
(4) four or more comorbidities. Time on clinic wait list was measured as the number of days from the referral date to the date seen in clinic. Duration of symptoms was reported by the caregiver who was asked for how long the patient's memory problems had been a real concern. This variable was measured in years. The metropolitan influence zone (MIZ) classification, developed by researchers at Statistics Canada, classifies communities that lie outside census metropolitan areas (CMAs) and census agglomerations (CAs) according to the degree of influence that CMA/CAs have on the community. The MIZ recognizes inherent social, economic and geographic characteristics of different communities and is used by the RRMC as a measure of 'ruralness.' The patient's hometown was categorized into the following groups: (1) CMA/CA, (2) strong MIZ, (3) moderate MIZ, (4) weak MIZ, and (5) no MIZ.

Caregiver-rated functional status of the patient was assessed by two scales: the Functional Assessment Questionnaire (FAQ) ${ }^{18}$ and the Neuropsychiatric Inventory Scale (NPI). ${ }^{19}$ The FAQ is a ten item screening tool for assessing independence in daily activities and universal skills among older adults. Each item is scored on a scale from 0 (independence) to 3 (dependence). Scores are summed giving a total ranging from 0 to 30 , where a

Table 1: Socio-demographic, functional and clinical characteristics of patients at clinic day

\begin{tabular}{|c|c|c|}
\hline Continuous variable & Mean \pm SD & Range \\
\hline Age & $73.9 \pm 9.2$ & $42-91$ \\
\hline Formal education (years) & $10.7 \pm 3.0$ & $3.5-19.0$ \\
\hline Wait time (days) & $173.9 \pm 74.7$ & $13-422$ \\
\hline Duration of symptoms (years) & $1.9 \pm 1.8$ & $0-12$ \\
\hline 3 MS score ${ }^{a}$ & $71.9 \pm 18.7$ & $0-99$ \\
\hline NPI score ${ }^{\mathrm{b}}$ & $8.3 \pm 6.3$ & $1-30$ \\
\hline FAQ score ${ }^{c}$ & $13.8 \pm 8.0$ & $0-30$ \\
\hline ZBS score s $^{d}$ & $13.5 \pm 8.8$ & $0-48$ \\
\hline BSI (Global Severity Index score) ${ }^{\mathrm{e}}$ & $51.0 \pm 10.0$ & $33-80$ \\
\hline Categorical variable & & n (\%) \\
\hline \multicolumn{3}{|l|}{ Gender } \\
\hline Male & & $76(38.4)$ \\
\hline Female & & $122(61.6)$ \\
\hline \multicolumn{3}{|l|}{ Ancestry } \\
\hline North American Indian/Aborginal/Métis & & $11(5.6)$ \\
\hline European & & $150(75.8)$ \\
\hline Other & & $9(4.5)$ \\
\hline Unknown & & $28(14.1)$ \\
\hline \multicolumn{3}{|l|}{ Marital status } \\
\hline Married/common-law & & $130(65.7)$ \\
\hline Single/divorced/separated/widowed & & $56(28.3)$ \\
\hline Unknown & & $12(6.1)$ \\
\hline \multicolumn{3}{|l|}{ Number of people living with patient } \\
\hline 0 & & $41(20.7)$ \\
\hline 1 & & $125(63.1)$ \\
\hline$\geq 2$ & & $32(16.2)$ \\
\hline \multicolumn{3}{|l|}{ Number of patient comorbidities } \\
\hline$\leq 1$ & & $8(4.0)$ \\
\hline 2 & & $18(9.1)$ \\
\hline 3 & & $26(13.1)$ \\
\hline$\geq 4$ & & $134(67.7)$ \\
\hline Unknown & & $12(6.1)$ \\
\hline \multicolumn{3}{|l|}{ Family history of dementia } \\
\hline Yes (positive) & & $94(47.5)$ \\
\hline No (negative) & & $87(43.9)$ \\
\hline Unknown & & $17(8.6)$ \\
\hline \multicolumn{3}{|l|}{ Metropolitan Influence Zone } \\
\hline CMA/CA & & $71(35.9)$ \\
\hline None & & $20(10.1)$ \\
\hline Weak & & $69(34.8)$ \\
\hline Moderate & & $30(15.2)$ \\
\hline Strong & & $8(4.0)$ \\
\hline
\end{tabular}

a. 3 MS Possible score range $=0-100$; . NPI possible score range $=1-36$; . FAQ possible score range $=0-30$;

d. ZBS possible score range $=0-48$; e. BSI possible score range $=33-80$ (female) and 35-80 (male);

$3 \mathrm{MS}=$ Modified Mini-Mental State Examination, NPI = Neuropsychiatry Inventory, FAQ $=$ Function

Assessment Questionnaire, ZBS = Zarit Burden Scale, BSI = Brief Symptom Inventory, CMA = Census

Metropolitan Area, $\mathrm{CA}=$ Censes Agglomeration 
Table 2: Neurologist's diagnosis at clinic day

\begin{tabular}{ll}
\hline Diagnosis & $\mathbf{n}(\%)$ \\
\hline Alzheimer's disease & $101(51.0)$ \\
Mild cognitive impairment $^{\mathrm{a}}$ & $33(16.7)$ \\
Frontotemporal dementia $^{\mathrm{b}}$ & $20(10.1)$ \\
Vascular dementia $^{\mathrm{c}}$ & $14(7.1)$ \\
Lewy Body dementia & $13(6.6)$ \\
Dementia due to other etiologies & \\
\hline
\end{tabular}

a. Mild cognitive impairment (MCI) includes amnestic and non-amnestic subtypes; b. Frontotemporal dementia (FTD) includes FTD frontal variant, FTD semantic and FTD progressive non-fluent; c. Vascular dementia includes vascular dementia and vascular cognitive impairment; d. Dementia due to other etiologies includes: Parkinson's disease, Huntington's disease, normal pressure hydrocephalus, and other dementias

higher score indicates a higher level of patient dependency. The NPI was developed to measure behavioural changes in patients with Alzheimer's disease and other dementias. For this study, only one component of the NPI scale, NPI-Severity (NPI-S), was used. The NPI-S consists of 12 items scored on a scale from 1 (mild) to 3 (severe). These scores are summed to give a severity score ranging from 1 to 36 , where higher scores indicate more severe psychiatric symptoms.

Self-rated caregiver burden was assessed through a short version of the Zarit Burden Interview (ZBI) ${ }^{20,21}$ which includes 12 items scored from 0 (never) to 4 (almost always). Summed scores range from 0 to 48 where higher scores indicate higher caregiver burden. The Brief Symptom Inventory (BSI) ${ }^{22}$ was used to assess caregiver psychological distress and symptoms. The BSI is a 53-item psychological self-reported symptom inventory that requires the caregiver to rate the degree to which potential problem areas have distressed them over the past seven days. Each item can be scored from 0 (not distressed at all) to 4 (extremely distressed). Scores are calculated by summing all responses and dividing by the number of questions answered. This fraction is located in the BSI manual to determine the caregiver's Global Severity Index (GSI) score. Global Severity Index scores range from 33 to 80 for females and from 35 to 80 for males, where higher scores indicate higher levels of caregiver distress.

\section{Outcome: Cognitive Impairment}

The dependent variable in this study was level of patient cognitive impairment at clinic day presentation. Data regarding the cognitive status of the patients was collected using the Modified Mini-Mental State Examination (3MS). ${ }^{23}$ The $3 \mathrm{MS}$ cognitive screen was derived from the Mini-Mental State Examination, ${ }^{24}$ but includes four additional items (date and place of birth, animal naming, similarities, and a second recall task), is scored up to 100 points to provide finer discrimination, and samples a broader range of cognitive capacity and difficulty levels. It has been shown to be a more sensitive measure of cognitive impairment than the MMSE. ${ }^{25}$ Lower $3 \mathrm{MS}$ scores indicate more severe cognitive impairment.

\section{Statistical Analysis}

Data underwent statistical analysis using SPSS version 18 software. Descriptive analysis was performed on all variables to characterize the sample. Measures of covariance of the independent variables were completed. If two or more variables were highly correlated (variance inflation factor greater than approximately two) the more relevant measure referenced in the literature was included in the regression. A bivariate linear regression analysis was carried out to examine the association between each potential independent variable with the outcome variable $3 \mathrm{MS}$ scores.

A multiple regression analysis was performed using a manual backward selection process to determine the influence of the variables on the severity of cognitive impairment as measured by the $3 \mathrm{MS}$. An initial multivariate regression model was constructed including all the variables that presented $p<0.2$ in the bivariate linear regression. This model underwent adjustment by excluding one variable at a time using non-significance as the criterion until the final model was obtained. A p-value less than 0.05 was considered statistically significant. We constructed 95\% confidence intervals for each variable in the regression model. The coefficient of multiple determination, R2, explains the proportionate reduction of total variation of outcome associated with the set of independent variables used and was reported for the final multiple regression model.

\section{RESULTS}

\section{Study population}

Our sample was comprised of 198 patients (Table 1: patient characteristics), with the most common diagnosis being Alzheimer's disease (51.0\%), followed by mild cognitive impairment (16.7\%) (Table 2: neurologist's diagnosis). The mean patient age at the clinic day appointment was 73.9 years $(\mathrm{SD}=9.2$ years). The majority were female $(62.1 \%)$, over half were married or common-law $(65.7 \%)$ and most were of European ancestry (75.8). Average 3MS score was 71.9 $(\mathrm{SD}=18.7$, range $=0-99)$.

\section{Bivariate and multivariate analyses}

Variables underwent analysis in the bivariate linear regression analysis with $3 \mathrm{MS}$ score as the dependent variable (Table 3). Age, years of formal education, family history of dementia, Asian or African ancestry, number of comorbidities, symptom duration, moderate MIZ, NPI score, FAQ score, and BSI score were selected after bivariate regression analysis and included in the multiple regression analysis (all $\mathrm{p}<0.2$ ). Patient age $(\mathrm{p}<0.1)$, years of formal education, FAQ score and caregiver BSI score remained significant $(p<0.05)$ in the final multivariate regression model (Table 4a/4b). In compliance with the Canadian Institutes of Health Research guidelines, gender was integrated into the research design by including this variable in 
Table 3: Bivariate regression analysis

\begin{tabular}{|c|c|c|}
\hline Variable & Estimate $\pm \mathrm{SE}$ & p value \\
\hline Age & $-0.57 \pm 0.14$ & $<0.0001$ \\
\hline \multicolumn{3}{|l|}{ Gender (patient) ${ }^{a}$} \\
\hline Male & $-0.810 \pm 2.74$ & 0.767 \\
\hline \multicolumn{3}{|l|}{ Marital status ${ }^{\mathrm{b}}$} \\
\hline Single/divorced/separated/widowed & $3.98 \pm 2.99$ & 0.185 \\
\hline Formal education (years) & $1.58 \pm 0.45$ & 0.001 \\
\hline \multicolumn{3}{|l|}{ Family history of dementia ${ }^{c}$} \\
\hline Positive family history & $4.27 \pm 2.79$ & 0.128 \\
\hline \multicolumn{3}{|l|}{ Ancestry ${ }^{\mathrm{d}}$} \\
\hline North American Indian/Aboriginal/Metis & $-3.06 \pm 5.73$ & 0.594 \\
\hline Other & $-15.27 \pm 6.29$ & 0.016 \\
\hline \multicolumn{3}{|l|}{ Number of comorbidities ${ }^{e}$} \\
\hline 2 & $20.31 \pm 7.78$ & 0.010 \\
\hline 3 & $24.17 \pm 7.40$ & 0.001 \\
\hline$\geq 4$ & $22.41 \pm 6.66$ & 0.001 \\
\hline \multicolumn{3}{|l|}{ Number of people living with patient ${ }^{\dagger}$} \\
\hline 0 & $4.24 \pm 4.41$ & 0.337 \\
\hline 1 & $0.37 \pm 3.70$ & 0.920 \\
\hline Wait time (days) & $-0.01 \pm 0.02$ & 0.614 \\
\hline Symptom duration (years) & $-1.88 \pm 0.82$ & 0.023 \\
\hline \multicolumn{3}{|l|}{ Metropolitan Influence Zone ${ }^{g}$} \\
\hline None & $1.57 \pm 4.74$ & 0.741 \\
\hline Weak & $1.88 \pm 3.17$ & 0.553 \\
\hline Moderate & $5.50 \pm 4.08$ & 0.179 \\
\hline Strong & $7.82 \pm 6.99$ & 0.264 \\
\hline NPI & $-0.42 \pm 0.23$ & 0.073 \\
\hline FAQ & $-0.97 \pm 0.16$ & $<0.0001$ \\
\hline ZBS & $-0.26 \pm 0.15$ & 0.089 \\
\hline BSI (Global Severity Index score) & $0.20 \pm 0.14$ & 0.147 \\
\hline
\end{tabular}

a. Gender (patient): reference is female; b. Marital status: reference is married/common-law; c. Family history of dementia: reference is negative family history; $d$. Ancestry: reference is European ancestry; e.

Comorbidities: reference is $\leq 1$ comorbidity; $\mathrm{f}$. Number of people living with patient: reference is $\geq 2$ roommates; g. Metropolitan Influence Zone: reference is CMA/CA; Notes: $\mathrm{p}<0.2 ; 3 \mathrm{MS}=$ Modified Mini-Mental State Examination, NPI = Neuropsychiatry Inventory, FAQ = Function Assessment Questionnaire, ZBS = Zarit Burden Scale, BSI = Brief Symptom Inventory, CMA = Census Metropolitan Area, CA = Censes Agglomeration

Table 4a: Multiple regression analysis

\begin{tabular}{llll}
\hline Variable & Estimate $\pm \mathbf{S E}^{\mathrm{a}}$ & $\begin{array}{l}\mathbf{9 5 \%} \mathbf{C l} \text { for } \\
\text { Estimate }\end{array}$ & p value \\
\hline Age & $-0.264 \pm 0.142$ & $(-0.55,0.016)$ & 0.064 \\
Gender (patient) $_{\text {Male }}^{\text {b }}$ & & $(-7.42,2.64)$ & 0.349 \\
Formal education (years) $_{\text {FAQ }^{c}}$ & $-2.39 \pm 2.545$ & $(0.16,1.82)$ & 0.020 \\
BSI (Global Severity Index score) $^{\mathrm{d}}$ & $0.991 \pm 0.421$ & $(-1.15,-0.50)$ & $<0.0001$ \\
\hline
\end{tabular}

a. Adjusting for sex; b. Gender (patient): female is reference; c. Higher FAQ score indicates higher level of patient dependency; d. Higher BSI score indicates higher level of caregiver distress; Notes: R2 (coefficient of multiple determination for regression $)=0.261 ; \mathrm{p}<0.10$ for age variable, $\mathrm{p}<0.05$ for all other variables; $\mathrm{SE}=$ Standard Error, $\mathrm{CI}=\mathrm{Confidence}$ Interval, FAQ = Functional Assessment Questionaire, BSI = Brief Symptom Inventory 
Table 4b: Multiple regression analysis

\begin{tabular}{|c|c|c|c|}
\hline Variable & Estimate $\pm \mathrm{SE}^{\mathrm{a}}$ & $\begin{array}{l}95 \% \mathrm{Cl} \text { for } \\
\text { Estimate }\end{array}$ & $p$ value \\
\hline Age & $-0.034 \pm 0.175$ & $(-0.38,0.31)$ & 0.844 \\
\hline \multicolumn{4}{|l|}{ Gender (patient) } \\
\hline Male $^{\mathrm{b}}$ & $39.08 \pm 19.734$ & $(0.10,78.06)$ & 0.049 \\
\hline Formal education (years) & $0.914 \pm 0.417$ & $(0.09,1.74)$ & 0.030 \\
\hline$F A Q^{c}$ & $-0.791 \pm 0.164$ & $(-1.11,-0.47)$ & $<0.0001$ \\
\hline BSI (Global Severity Index score) ${ }^{d}$ & $0.263 \pm 0.125$ & $(0.02,0.51)$ & 0.037 \\
\hline Age Gender (Male) & $-0.551 \pm 0.264$ & $(-1.07,-0.03)$ & 0.039 \\
\hline
\end{tabular}

a. Adjusting for sex; b. Gender (patient): female is reference; c. Higher FAQ score indicates higher level of patient dependency; d. Higher BSI score indicates higher level of caregiver distress; Notes: R2 (coefficient of multiple determination for regression $)=0.279 ; \mathrm{p}<0.10$ for age variable, $\mathrm{p}<0.05$ for all other variables; $\mathrm{SE}=$ Standard Error, $\mathrm{CI}=\mathrm{Confidence}$ Interval, FAQ = Functional Assessment Questionaire, BSI = Brief Symptom Inventory

our regression models. By including gender in the framework, we made certain any effects of this variable would be captured in the model. An age and gender interaction term was created. The regression analysis was repeated to include this variable, which proved significant $(\mathrm{p}<0.05)$. Four variables emerged as significant predictors of more severe cognitive decline at clinic day, including higher FAQ score (indicating greater patient dependency in daily activities and universal skills). A higher level of formal education and higher BSI score, which suggests higher levels of caregiver psychological distress, predicted less severe cognitive impairment at initial clinic presentation. There was a significant interaction between age and gender, where the relationship between gender and level of cognitive impairment depended on age: in younger patients, females were more cognitively impaired, while in older patients males were more impaired at clinic day (Table 4b).

The identity of the primary caregiver (husband, wife, son, daughter, other) and whether this relationship had an effect on the age and gender interaction was also examined. The majority of primary caregivers were female $(60 \%)$. We found that the caregiver gender and relationship to the patient had no significant effect on $3 \mathrm{MS}$ score at clinic presentation $(\mathrm{p}=0.308)$. The analysis was repeated to assess whether the gender of the patient and the gender of their caregiver affected 3MS score; again, there was no significant association $(\mathrm{p}=0.161)$. When we repeated the analysis to assess the effect of caregiver gender in older patients (age $>80$ ), there was no significant interaction $(\mathrm{p}=0.304)$.

\section{DISCUSSION}

The study objective was to identify socio-demographic, clinical and functional predictors of more severe cognitive impairment at clinic presentation in a rural population. We found patient age, fewer years of formal education, poorer functional ability, and less caregiver psychological distress, and an age and gender interaction were statistically significant predictors.

There are numerous strengths in the present paper. Our sample includes non-institutionalized patients with heterogeneous ancestral backgrounds, allowing our findings to be generalized to a larger population. We included an extensive list of independent variables in our model, including both patient and caregiver variables. Although the $3 \mathrm{MS}$ is not as widely used as the MMSE, the additional questions and expanded scores increase the accuracy in measuring cognitive impairment.

Education has been thought to play a significant, complex role in the risk and progression of Alzheimer's disease and related dementias. While there is evidence that a higher level of education decreases the risk of developing dementia, ${ }^{26-28}$ faster rates of cognitive decline have been described in more highly educated Alzheimer's patients. ${ }^{29-31}$ A 2009 systematic review of the effect of education on Alzheimer's disease survival did not show any association between education and post-diagnosis survival. ${ }^{32}$ Additionally, the Chicago Health and Aging Project, a study that included over 6000 participants, did not find that education affected rates of cognitive decline. ${ }^{33} \mathrm{We}$ found that education level was positively associated with $3 \mathrm{MS}$ score, where those with more years of formal education performed better at the clinic day appointment. Similarly, lower education level has previously been associated with greater disease severity at presentation, suggesting later detection and referral of these patients. ${ }^{34}$ It is difficult to tease out the exact effect of education on cognitive performance as it is closely linked to both socioeconomic status and gender. ${ }^{28}$

It was hypothesized that those with a family history of dementia may present to the memory clinic earlier in their disease process, as family members would be more informed about the disease and more alert to early symptoms. A study exploring diagnosis of dementia in a rural setting showed that time from symptom onset to diagnosis was largely dependent on family recognition of the disease. ${ }^{5}$ While a positive family history was associated with better $3 \mathrm{MS}$ score in the univariate regression analysis, it became insignificant in the multiple regression analysis.

Better patient cognitive function at clinic presentation was associated with high levels of caregiver psychological distress. One explanation for this somewhat paradoxical finding is that, because higher levels of cognitive functioning suggest that the patient is earlier in the disease process, perhaps patients and their 
caregivers have had little contact with health care professionals at this point. While the caregiver may be noticing symptomatic changes in their loved one, they have yet to receive any diagnosis, information or support and are coping with these changes, along with any psychiatric problems they themselves may have, alone. Conversely, another explanation is that the psychological distress experienced by caregivers was established prior to the patient's dementia onset. In this case, the caregiver may already be in contact with health care providers regarding their own health issues, increasing the opportunity for the patient's symptoms to be recognized earlier. Additionally, caregivers who have better psychological health may possess an increased capacity to care for their family member for a longer period of time without consulting professional help, so at clinic presentation the patient is further along in their disease process. Further research into caregiver health in rural populations is needed.

Our finding that poor functional ability predicted more severe cognitive decline at clinic presentation is both expected and consistent with other results in the literature. Those with compromised performance with independent (complex) activities of daily living and other basic activities of daily living (dressing, grooming, bathing) have a greater chance of exhibiting more severe degrees of dementia, ${ }^{35,36}$ indicating more evolved disease progression.

We found that in our younger patients, females exhibited more cognitive impairment at clinic day, while in older patients, males were more cognitively impaired. This finding is congruent with previous research showing that women have an increased likelihood of being diagnosed with dementia at a later stage relative to men, ${ }^{37}$ and are more likely to have had a longer duration of symptoms before presentation..$^{38}$ This apparent delay in referral experienced by younger females may be related to traditional gender roles common in this cohort of older rural patients. Younger men may still be employed in the community workforce where changes in cognitive functioning would be noticed by others. In contrast, cognitive decline in younger women who fulfill the traditional homemaker role may be less evident. In addition, aggression in Alzheimer's disease has been related to male gender. ${ }^{39}$ Our younger male patients may be referred earlier because their aggressive symptoms are promptly recognized by caregivers.

The finding that older males tended to present to the memory clinic with more severe cognitive impairment compared to older females may again be due in part to traditional gender roles common in rural farming communities. Females (wives, daughters) may adapt to the role of primary caregiver with more affinity compared to men, as this role is more consistent with the traditional female gender role. In a previous study conducted by the Rural and Remote Memory Clinic team, women reported more caregiver burden, more severe distress, and lower mental health. ${ }^{40}$ This may be evidence of women acting as primary caregiver and adapting to this job for a longer period of time, resulting in their husbands or fathers being referred on to the memory clinic later along in their disease course. In addition, it is known the females have a greater life expectancy than males. ${ }^{41}$ In our older patient population, we may see that better cognitive functioning in older females is a reflection of increased longevity, and with more years of life available in the future, older female patients are at an earlier stage in the natural disease progression than their male counterparts.

Timely detection, diagnosis, and treatment of dementia ultimately involves many complex factors. The multiple regression analysis coefficient of determination, or R2 value, (0.279) likely reflects the dynamic relationship between rural patients, their primary care providers, and health care system constraints that contribute to timing of presentation at a memory clinic. The Alzheimer Society of Canada's 2010 recommendations for a national dementia strategy include both increasing awareness of the importance of prevention and early intervention, and recognizing the critical role played by informal caregivers. ${ }^{1}$ This study addresses and furthers our understanding of these topics and indentifies areas for future research.

\section{ACKNOWLedgMents}

Study funding: Supported by College of Medicine, University of Saskatchewan and the Mach-Gaensslen Foundation Grant. The authors thank the Rural and Remote Memory Clinic team.

\section{REFERENCES}

1. Rising tide: The impact of Dementia on Canadian Society Executive Summary. Alzheimer Society of Canada. 2010.

2. Innes A, Morgan D, Kostineuk J. Dementia care in rural and remote settings: A systematic review of informal/family caregiving. Maturitas. 2011;68:34-46.

3. The Canadian Study of Health and Aging Working Group. Patterns and health effects of caring for people with dementia. The impact of changing cognitive and residential status. Gerontologist. 2002;42:643-52.

4. Keefover RW, Rankin ED, Keyl PM, et al. Dementing illnesses in rural populations: the need for research and challenges confronting investigators. J Rural Health. 1996;12(3):178-87.

5. Teel CS. Rural practitioners' experiences in dementia diagnosis and treatment. Aging Ment Health. 2004;8(5):422-9.

6. Statistics Canada, Census of Population, 1851 to 2006: Population, urban and rural, by province and territory. Available from: http://www40.statcan.ca/101/cst01/demo62i-eng.htm

7. Projected population, by projection scenario, sex and age group as of July 1, Canada, provinces and territories, annual (CANSIM table 052-0005). Ottawa: Statistics Canada, 2010. Available from: http://www4.hrsdc.gc.ca/.3ndic.1t.4r@-eng.jsp?iid=33

8. Bradford A, Kunik ME, Schulz P, Williams SP, Singh H. Missed and delayed diagnosis of dementia in primary care. Alzheimer Dis Assoc Discord. 2009;23:306-14.

9. Innes A, Cox S, Smith A, Mason A. Service provision for people with dementia in rural Scotland: difficulties and innovations. Dementia. 2006;5(2):249-70.

10. Morgan DG, Crossley M, Kirk A, et al. Improving access to dementia care: development and evaluation of a rural and remote memory clinic. Aging Ment Health. 2009;13:17-30.

11. Morgan DG, Crossley M, Kirk A, et al. Evaluation of telehealth for preclinic assessment and follow-up in an interprofessional rural and remote memory clinic. J App Gerontol. 2011;30(3):304-31.

12. Boller F, Verny M, Hugonot-Diener L, Saxton J. Clinical features and assessment of severe dementia. A review. Eur J Neurol. 2002;9:125-36

13. McKhann G, Drachman D, Folstein M, et al. Clinical diagnosis of Alzheimer's disease: report of the NINCDS-ADRDA work group under the auspices of department of health and human services task force on Alzheimer's disease. Neurology. 1984; 34:939-44.

14. McKeith IG, Galasko D, Kosaka K, et al. Consensus guidelines for the clinical and pathologic diagnosis of dementia with Lewy bodies (DLB): report of the consortium on DLB international workshop. Neurology. 1996;47:1113-24. 
15. Roman GC, Tatemichi TK, Erkinjuntti T, et al. Vascular dementia: diagnostic criteria for research studies. Report of the NINDSAIREN International Workshop. Neurology. 1993;43(2):250-60.

16. Neary D, Snowden JS, Gustafson L, et al. Frontotemporal lobar degeneration: a consensus on clinical diagnostic criteria. Neurology. 1998;51:1546-54.

17. McNiven C, Puderer H, Janes D. Census metropolitan area and census agglomeration influenced zones (MIZ): a description of the methodology. 2000. Ottawa: Statistics Canada, Geography Division .

18. Pfeffer R, Kurosaki T, Harrah C, Chance J, Filos S. Measurement of functional activities in older adults in the community. $\mathrm{J}$ Gerontology. 1982;37:323-9.

19. Cummings J, Mega M, Gray K, Rosengerg-Thompson S, Carusi D, Gornbien J. The Neuropsychiatric Inventory: Comprehensive assessment of psychopathology in dementia. Neurology. 1994; 44:2308-14.

20. Bedard M, Molloy M, Squire L, Dubois S, Lever J, O’Donnell M. The Zarit Burden Interview: A new short version and screening version. Gerontologist. 2001;41:652-7.

21. O'Rourke N, Tuokko H. Psychometric properties of an abridged version of the Zarit Burden Interview within a representative Canadian caregiver sample. Gerontologist. 2003;43:121-7.

22. Derogatis L, Melisaratos N. The brief symptom inventory: An introductory report. Psychol Med. 1983;13:595-605.

23. Teng EL, Chui HC. The modified Mini-Mental State (3MS) Examination. J Clin Psychiatr. 1987;48:314-8.

24. Folstein MF, Folstein SE, McHugh PR. "Mini-mental state". A practical method for grading the cognitive state of patients for the clinician. J Psychiatr Res. 1975;12:189-98.

25. McDowell I, Kristjansson B, Hill GB, Hebert R. Community screening for dementia: the Mini Mental State Exam (MMSE) and the Modified Mini-Mental State Exam (3MS) Compared. J Clin Epidemiol. 1997;50:377-83.

26. Ngandu T, von Strauss E, Helkala EL, et al. Education and dementia: what lies behind the association? Neurology. 2007;69: 1442-50.

27. Karp A, Kareholt I, Qiu C, Bellander T, Winblad B, Fratiglioni L. Relation of education and occupation-based socioeconomic status to incident Alzheimer's disease. Am J Epidemiol. 2004; 159:175-83.

28. Chen J, Lin K, Chen Y. Risk Factors for Dementia. J Formos Med Assoc. 2009;108(10):754-61.

29. Scarmeas N, Albert SM, Manly JJ, Stern Y. Education and rates of cognitive decline in incident Alzheimer's disease. J Neurol Neurosurg Psychiatry. 2006;77:308-16.
30. Musicco M, Salamone G, Caltagirone C, et al. Neuropsychological predictors of rapidly progression patient with Alzheimer's disease. Dement Geriatr Cogn. 2010;30(3):219-28.

31. Mussico M, Palmer K, Salamone G, et al. Predictors of progression of cognitive decline in Alzheimer's disease: the role of vascular and sociodemographic factors. J Neurol. 2009;256:1288-95.

32. Paradise M, Cooper C, Livingston G. Systematic review of the effect of education on survival in Alzheimer's disease. Int Psychogeriatrics. 2009;21:25-32.

33. Wilson RS, Hebert LE, Scherr PA, Barnes LL, Mendes de Leon CF, Evans DA. Educational attainment and cognitive decline in old age. Neurology. 2009;72:460-5.

34. Moritz DJ, Petitti DB. Association of education with reported age of onset and severity of Alzheimer's disease at presentation: implication for the use of clinical samples. Am J Epidemiol. 1993; 137:456-62.

35. Marra TA, Pereira DS, Faria CDCM, Tirado LSM, Pereira LSM. Influence of socio-demographic, clinical and functional factors on the severity of dementia. Arch Gerontol Geriat. 2011;53: $210-5$.

36. Njegovan V, Man-Son-Hing M, Mitchell SL, Molnar FJ. The hierarchy of functional loss associated with cognitive decline in older persons. J Gerontol A Biol Sci Med Sci. 2001;56A: M63843.

37. Cattel C, Gambassi G, Sgadari A, Zuccala G, Carbonin P, Bernabei R. Correlates of delayed referral for the diagnosis of dementia in an outpatient population. J Gerontol A Biol Sci Med Sci. 2000;55A:M98-M102.

38. Swanwich GRJ, Coen RF, Maguire CP, et al. The association between demographic factors, disease severity and the durations of symptoms at clinical presentation in elderly people with dementia. Age Ageing. 1999;28:295-9.

39. Ott BR, Tate CA, Gordon NM, Heindel WC. Gender differences in the behavioural manifestations of Alzheimer's disease. J Am Geriatr Soc. 1996;44:583-7.

40. Steward N, Morgan D, Cammer D, Karunanayake C, Minish D. Gender differences in caregiver distress over time. Poster presented at the 26th International Conference of Alzheimer's Disease International, March 2011, Toronto, Ont.

41. Statistics Canada, Life tables, Canada, Provinces and Territories, 2000-02. Life expectancy at birth, by sex, by province: http://www.statcan.gc.ca/tables-tableaux/sum-som/101/cst01/ health26-eng.htm 